\title{
Creating role models of reading - Through national, regional and local competitions
}

\author{
Maria Eriksen \\ Head of communications \\ Municipal Association of School Libraries in Denmark \\ Denmark
}

\begin{abstract}
To improve the reading abilities of students in sixth grade several pilot projects have used national, regional and local competition to prove that reading is cool. The aim is to create role models of reading instead of book droppers. This paper describes two of these projects: "The national championship of reading" and "Ready, set, answer". "The national championship of reading" is inspired by a similar Dutch project. The aim of the competition is to make it prestigious to read and be good at reading aloud. "Ready, set, answer" is a quiz, which is build around all kinds of reading. This competition is not focused only on novels.
\end{abstract}

Reading, role models, competition

\section{Background information}

Over the past few years there has been great focus on reading in the first to third grade in Danish schools. PISA - Programme for International Student Assessment - showed that Danish students were far behind other European countries, when it came to teaching young children to read. After a few years of successful actions to improve the reading of young children the attention was drawn to students in the fourth to sixth grade.

The reading of first to third grade students has been greatly improved, but in failing to continue the efforts after the third grade, Danish schools experienced a greater amount of book droppers in the fourth to sixth grade.

To counter this development, several pilot projects arose. The strategy was to prove that reading was not for nerds. Readers should be considered role models. Several of these projects were very successful and have grown from local to national projects. This paper will describe two of these projects: "The national championship of reading" and "Ready, set, answer".

Both of these projects have been economically supported by the "Desire to read" campaign, which is a joint initiative between The Ministry of Culture, The Ministry of Education and The Ministry of Family and Consumer Affairs. The "Desire to read" campaign was initiated in May 2004 and was ended in 2007. The aim of the campaign was to "inspire children and young adults to read and experience the wonderful world of books". The goal of the campaign further states: "Books are but a part of the media use of children and young adults and therefore it is necessary to combine interactive experiences with the books."

It has recently been announced that the three ministries behind the campaign has decided to grant the campaign 4.3 million DKK (approximately 900.00 USD) every year starting in 2008 through to 2010. In this new part of the campaign around half the money will be put into continuing projects that are considered excellent examples. Both of the projects described in this paper are amongst the four projects receiving these special funds. 


\section{"The national championship of reading"}

"The national championship of reading" is inspired by a similar Dutch project. The aim of the competition is to make it prestigious to read and be good at reading aloud. To make it cool to read, the competition creates a fun and exciting environment to read aloud in. The project is a cooperation between public libraries and schools which wish to participate in the competition.

The competition was originally initiated by public libraries of two major cities in Denmark, and it is up to the individual library to decide if they wish to participate. Only schools in the area of a participating library can join in the competition.

The public libraries are hosts of the competition. They invite all schools (private as well as public) in their area to participate. Only grade six students can participate in the competition. Each participating school can submit one student to the first step of the competition. It is up to the individual school how they wish to select this student. Some schools choose to have a contest amongst their students to find the best reader. Other schools choose to let the classes of sixth grade decide on the best reader amongst themselves. Either way it creates an opportunity to acknowledge other competencies than popularity, as the most popular boy or girl in the class is not necessarily the best person to represent the school further on in the competition.

The representatives from the participating schools in the municipality compete against each other at the local public library in the first step of the competition. All contestants bring their class mates to the reading.

All contestants read a page in a book they have chosen themselves. Before they start reading they must introduce the book and explain why they have chosen this book. After reading the text of their choice, the contestants must read a piece of unknown text.

The contestants are judged on five different qualities in their reading.

1. Understanding of the text: The contestant chooses a paragraph in a novel or an anthology. The paragraph has to be chosen in a way that allows the text to give meaning to the listeners. Previous to the reading the contestant must briefly account for the author, the title of the book, characters appearing in the paragraph and the storyline previous to the chosen paragraph. The reading and the introduction must last five minutes: One minute for introduction and four minutes for reading aloud.

The contestants will be judged on the following:

- As an outsider, was it possible to understand everything that was read aloud?

- Did the introduction provide the listener with sufficient prior knowledge?

- Were the right places stressed throughout the reading?

2. Use of the voice: The contestant must read loud enough that the text can be heard but without the voice being strained. Furthermore, the contestant must display a personal interpretation of the text, but without overacting.

The contestants will be judged on the following:

- Is the text read loud without strain?

- Was the tone of voice appropriate for the story?

3. Pronunciation: The pronunciation must be careful, distinct and clear without being spelling pronunciation.

The contestants will be judged on the following:

- Is the pronunciation careful and distinct?

4. Pace: The contestant must give the text the pace it requires and be attentive of pauses.

The contestants will be judged on the following:

- Does the contestant read at an appropriate and pleasurable pace?

- Did varieties in the pace occur in places where this was necessary?

5. Contact with the audience: It is important that the reader does not have his or hers eyes fixed on the text throughout the reading (for this reason it is important to know the text well, yet without knowing it by heart). From time to time the contestant must be able to look up and make eye contact with the audience.

The contestants will be judged on the following: 
- Does the contestant from time to time look up and make eye contact with the audience?

- Did the audience listen to what was being read?

A panel of judges decides which student continues on in the competition. In this first step of the competition it is up to each library, who they choose for their panel of judges. An example could be a librarian, a local politician, a teacher with no relation to any of the schools participating in the contest and a journalist from the local paper.

The winner from each municipality continues to the semi finals at their regional library, where they meet the winners from all other participating libraries in their region. The process here is the same, and each region selects a contestant for the finals. Ten students participate in the final step of the competition.

In 2007 the finals was a big event arranged in association with the Danish Public Service TV channel DR. The ten finalists ventured to Aarhus in the northern part of Denmark with their class mates, where they met in a big show with well-known children's program hosts, entertainment and a buffet lunch. The judges in the panel were a famous Danish actor, an author, a rhetorical teacher and a children's culture consultant. After each reading one or two of the judges would point out weak and strong points in the contestants reading and suggest points for improvement.

For the second reading (reading of an unknown text) a big Danish publishing house had sponsored books for the contestants to read from. All contestants read a different piece, but from the same book. The publishing house awarded the contestants with a set of the book for each class.

After the second reading the judges decided on a winner of the competition. The winner was awarded with a cell phone by Nokia and a two day trip for the whole class to Scandinavia's biggest amusement park "Liseberg" in Göteborg, Sweden.

Furthermore, the winners of "The national championship of reading" were engaged in the outcome of another competition. The Danish Public Service Channel DR had held a competition for the best horror story written by a child earlier in the year. In this contest all children could submit their own horror story and the ten best stories were recorded in a studio by the ten finalists of "The national championship of reading". Both local and national press was present at the finals and considering that it was a competition for sixth graders the media interest was satisfying.

The school librarians who have had their schools participate in this project have generally appreciated this as a good opportunity to guide the classes in how to choose a good book to read. It has also offered a chance for extended collaboration with the class room teacher. Generally the students have had great interest in the books that other students have read from and this has increased their interest in reading and broadened their reading horizon.

A school library coordinator for one of the participating municipalities has expressed these advantages in the cooperation between public libraries and school libraries: The public libraries contacted the coordinating school librarian which offered a better opportunity for presentation of the concept. The public library can only communicate with the individual school by email or other written medias, but when involving the school library coordinator a whole other level of communication is opened. The coordinator has the opportunity to deliver the project orally to his or hers co-workers in each school. It is much easier to explain and engage, when you are facing the people in question. This way the school librarians from each school can get answers to all of their questions and therefore better communicate the concept to the class room teachers in question.

Another advantage is that by using this form of communication the school librarians are already familiar with the competition when a class room teacher requests advice and assistance in the organizing and choosing of books. By letting the school librarian assist in this part of the process you can help the students have a good reading experience. School librarians have much deeper knowledge of literature and which books are good to read aloud from. It is important to choose text without too much dialogue for example, as this is hard to read aloud. If a contestant progresses in the competition a school librarian can also offer help and guidance without time being taken from the rest of the class. On the other hand the public library offers a neutral space for the competition to take place. By using their facilities no class or contestant have the home field advantage and everyone is offered equal opportunities. 
To help the students as well as the school librarians and class room teachers guiding the students, the organizers developed this list of advice:

How do I choose a good book?

Here is some advice to help you, when you are trying to choose a good book and a paragraph to read aloud from:

- You should choose a book which you like. If you choose a paragraph from a novel, make sure to find a well rounded piece or a short chapter.

- Try to read a section of the book aloud to determine if the book is good to read aloud from. This way you also know how long it takes to read a page.

- Make sure that there are not too many characters appearing in the paragraph, as this will be confusing for the listeners. You should also make sure that there is not too much dialogue in your paragraph.

- If you find it hard to choose a good book, ask your teacher or your school librarian for help.

How do I practice?

- Practice often in reading aloud. Try reading for yourself, for your class mates and for your parents. Ask them to comment on your reading. You can also try to record yourself on tape. This way you can listen to yourself afterwards.

- Make sure you understand the paragraph you have chosen completely. You should also make sure that you know exactly what has taken place in the paragraph previous to the one you are reading.

- Carefully read the advice below so you know, what the judges will take notice of at the competition.

How do I become the champion of reading?

- Begin by mentioning the author and the title of the book before you start reading aloud. After introducing these two elements you must briefly account for the storyline in the book and inform the listeners of things that are important for them to be able to understand the paragraph you have chosen. This could be introducing characters, which appear in the paragraph or explaining what has taken place right before your paragraph begins. The shorter the better.

- Do not read to fast. Take your time and make sure that the paragraph you have chosen fits the time frame (five minutes including the introduction). It is better to choose a slightly shorter paragraph than to have to read too fast towards the end.

- Speak clearly. Use your own natural voice and try to relax while you are reading.

- Make sure to have contact with your audience. Do not hold the book in front of your eyes, but look up from the text from time to time and try to make eye contact with someone in the audience. This is easier if you know the text well, but you should not know it by heart.

- Do not try to act. You should however use your voice to express the atmosphere in the text by raising and lowering your voice or changing the pace.

- Do not shout too loud. This is very important if at some point you have to read into a microphone.

- It does not matter if you make a mistake. Take a deep breath and start over on the sentence.

The students have commented that the participation in "The national championship of reading" has been a fun and engaging experience. They have gotten new ideas for books to read and it has strengthened their social solidarity. The students have also learned to appreciate new competencies in their fellow class mates.

\section{"Ready, set, answer"}

"Ready, set, answer" is another example of a project which wishes to improve the reading of grade six students. This project started out as a local initiative and was so successful that it is now a nation wide project. Like in "The national championship of reading" it is up to the individual school to choose their representatives. Each school selects a team of five students to represent them, and this team competes against other teams in the 
municipality. The winner moves on to the regional competition and in the end the winners of the regional semifinals meet in the national finals.

"Ready, set, answer" is a quiz, which is built around all kinds of reading. This competition is not focused only on novels. This is a very deliberate decision from the originators of the project as part of the goal is to show that reading is a crucial ability in life as well as proving that not only book lovers can be presented as role models of reading.

The competing teams will have 24 different categories presented to them. Each category contains three questions which the team has a short amount of time to answer as a whole. The categories cover many different subjects from Harry Potter to food recipes to children's songs to manuals of electronic equipment. Therefore it is important that each class chooses contestants with different competencies. Most of the teams progressing far in the competition had a similar team structure. The teams generally consisted of specialists within different fields and often one student with general knowledge of many fields to be the back up. The team often appointed one student as the team captain to allow the rest of the team to have more time to think as the team captain would take notes of the answer and deliver this to the quiz master.

As mentioned above the categories vary from literature to recipes and manuals to questions of relations between books and music or movies. Here are examples of six categories:

Stories of animals:

Kipling, author of "The jungle book", has written an exciting story of a brave little civet cat, which conquers a cobra and saves its human family.

What is the name of the civet cat, which has given name to the story?

Hans Christian Andersen:

How old is Hans Christian Andersen?

Where was he born?

What did he want to be before he became a poet?

What is he also known for?

Name that character:

"If the motorcycle was huge, it was nothing to the man sitting astride it. He was almost twice as tall as a normal man and at least five times as wide. He looked simply too big to be allowed, and so wild - long tangles of bushy black hair and beard hid most of his face, He had hands the size of trash can lids, and his feet in their leather boots were like baby dolphins."

Guess a sport:

Traditional English sport where you can talk about ball, bat, pitcher, bowler and wicket.

On the horse:

In this riding discipline horse and rider conduct exercises following a programme, which includes halt, walk, trot, canter, circles, flying changes and piaffe.

Name the athlete:

"It is not about the bike: My journey back to life" is the title of a book by a famous American biker. What is the name of the author?

2006, which was the second year of "Ready, Set, Answer," was a nationwide competition. 15 teams of grade six students competed against each other at the finals in Odense. 620 teams entered the competition and 80 teams went on to the semi-finals. The finals were a big event with a famous Danish rapper as the host and the winning team won a weekend trip for the whole class. 80 libraries had hosted the local competitions from the start and naturally the finals also took place in a library.

One of the initiators of the competition, who is also a teacher and has had the main contact with the school libraries throughout the competition, states: When starting a project like this it is very important to take the time frame into consideration. The schools have to be informed well in time, as they have to get the competition into their planning of the teaching for the whole year. Generally it takes time to get something like this started. The word has to spread and teachers and school librarians have to see the advantage of a reading 
competition. It takes at least a couple of years before it is really up and running. When making the questions there are also many things to take into consideration. The questions cannot be too easy, but they must also not be too hard. It is important that even the listeners feel that they are engaged, when the competition takes place. Another important issue is the language. Unfortunately it is not possible to just have the local libraries make their own questions. It would create too much of a difference in difficulty and language use. And when reaching the regional and national level it is also important that none of the questions contain any form of dialect. Part of the aim of this competition is to focus on collaborative learning. It is crucial for the success of the group that it consists of students with different competencies. In the finals in 2006 one of the questions was: Ready these instructions and make a paper air plane. Someone who knows all about Harry Potter is not necessarily good at this.

The Danish Centre for Children's Literature has conducted an investigation of the outcome of the completion in 2006 in cooperation with the arrangers. In this investigation a questionnaire was sent to 20 sixth grades across the country. It was targeted at classes where a team participated in the first step of the competition. Both students on the team and the rest of the class answered the questionnaires first part. The second part was only answered by students on the team participating in the competition. 98 participants answered the questionnaire. Furthermore, an interview session with 5 of the teams was conducted.

The aim of the investigation was to try to determine what creates a desire to read. However, the investigation gives great insight as to how the students have experienced being part of this competition. Most important to the students have been to show their peers that they have great knowledge through their reading and their reading ability. They have experienced great support from their class mates, their teachers and school librarians, their parents and the local community. The students also thought that the competition was a great way to introduce the public library to those of their class mates who does not normally use the library. They have also experienced that some of their class mates have turned against them, when they answered a question incorrectly and that some students have been jealous of the teams getting special treatment with for example soda and biscuits. This is not considered a problem by the teams, as the positive aspect of the competition has been far greater than the negative. Both teachers and the students on the teams have tried to counter the negative effects by talking about how to behave during the competition on the teacher's part and sharing their goods on the students' part.

The acknowledgement of competencies has also gone beyond the reading ability. In the original pilot project that only included six schools form one municipality many prejudices were put to shame. The winning team consisted of five boys from a private school. Not only did this prove that not all boys are book droppers, the local opinion was that this particular school did not teach the students what they needed to know. This is no longer the general assumption in the local community.

The investigation also looks at the role model aspect of the competition. Does "Ready, Set, Answer" create role models of reading? The students are asked how they came to be part of the competing team. Though the method of choosing the contestants is up to the school, the students generally volunteered, appreciating and understanding their own competencies within the field. This shows that the students in general already have confidence in their abilities and that they dare to stand up in front of their class mates and nominate them selves, after which their fellow students have had trust in their abilities and voted them as part of the team. As a result of this they can be characterized as confident, independent and competent representatives for the class. They seem to already have positions as role models. In conclusion the students on the teams are not made role models as they are already considered as such by their peers, but a special ability and knowledge is enhanced in their participation.

Furthermore, the schools participating in the "Ready, Set, Answer" have teachers and school librarians who have focus on reading and who are willing to invest time in projects concerning reading. In general this means that the competition does not necessarily reach the group of students who are not introduced to reading as a priority already. The challenge is to reach schools where teachers and teacher librarians do not prioritize reading projects and to engage students who are not already role models.

In the fall of 2008 "Ready, Set, Answer" is back after a one year break. Having received funds form the "Desire to read" campaign they are able to engage more students in alternative reading experiences. From 2008 and onwards the competition will be targeted at grade seven students in stead of grade six. This decision has been reached in cooperation with "The national championship of reading", as the two projects have found that it is very hard, if not impossible, for teachers and students to participate in both initiatives in one year. As most book droppers occur in the sixth and seventh grade the initiators of the two projects have concluded that these 
are the grades to focus on. As the students come into their teenage years, they are more reluctant to stand up in front of a crowd, which is why it has been chosen that "the national championship of reading" will continue in sixth grade, where as the team based project "Ready, Set, Answer" will move on to seventh grade students.

The project leader of "Ready, Set, Answer" states that they are very excited to reach this new group of students: "By changing our target group we also have to change our ways. The questions have to be harder and we have to find new categories. This is an excellent way of renewing the project and making sure it is constantly offering up to date questions and challenges"

Both of these competitions have been carried out as national projects. As described in the above they have started at local level, moved on to regional level and ended at the national level. Both projects would be able to take place only at local or regional level. There are several examples of school or municipalities where similar projects have been carried out in a smaller scale with the school library and the school librarians as project coordinators. The national level adds a lot to the contest and the students' experience of this, but schools, counties or municipalities which would wish to create projects inspired by these should not be discouraged if they are not able to do so on a national level.

\section{References}

Christensen, N. \& Lund, H. R. (2007). Hvad skaber en lystlæser? - en undersøgelse gennemført i et samarbejde mellem Gentofte Bibliotekerne og Center for Børnelitteratur. Gentofte, Denmark: Gentofte Bibliotekerne \& Center for Børnelitteratur.

www.smartparatsvar.dk

www.dotbot.dk/dm

Parts of the paper is inspired by conversations with Lissy Bech-Petersen, Kirsten Melchiorsen and Susanne Kier.

\section{Biographical notes}

Maria Eriksen has been employed with The Municipal Association of School Libraries in Denmark for three years. She is in daily contact with different professionals and officials from municipalities in Denmark. She is also co-editor of and writer for the journal "Børn \& Bøger".

\section{Statement of Originality}

This statement certifies that the paper above is based upon original research undertaken by the author and that the paper was conceived and written by the author(s) alone and has not been published elsewhere. All information and ideas from others is referenced. 